\title{
Diterpenoids from Azorella compacta (Umbelliferae) Active on Trypanosoma cruzi
}

\section{Jorge E Araya/+ , Iván Neira, Solange da Silva**, Renato A Mortara**, Patricio Manque, Esteban Cordero, Hernán Sagua, Alberto Loyola*, Jorge Bórquez* , Glauco Morales*, Jorge González}

Unidad de Parasitología, Departamento de Tecnología Médica *Laboratorio de Productos Naturales, Departamento de Química, Universidad de Antofagasta, Antofagasta, Chile **Disciplina de Parasitologia, Departamento de Microbiologia, Imunologia e

Parasitologia, Escola Paulista de Medicina, Unifesp, São Paulo, SP Brasil

The anti-Trypanosoma cruzi activity of natural products isolated from Azorella compacta was evaluated, with particular emphasis on their effect against intracellular amastigotes. Five diterpenoids from A. compacta derived from mulinane and azorellane were isolated and identified. Only two products, named azorellanol (Y-2) and mulin-11,3dien-20-oic acid (Y-5), showed trypanocidal activity against all stages of T. cruzi including intracellular amastigotes. At $10 \mu \mathrm{M}$, these compounds displayed a strong lytic activity. It ranged from $88.4 \pm 0.6$ to $99.0 \pm 1 \%$ for all strains and stages evaluate, with an $I_{50} / 18 \mathrm{~h}$ values of 20-84 $\mu \mathrm{M}$ and $41-87 \mu \mathrm{M}$, respectively. The development of intracellular amastigotes was also inhibited by nearly $60 \%$ at $25 \mu \mathrm{M}$. The trypanocidal molecules $Y-2$ and $Y-5$ did show different degrees of cytotoxicity depending on the cell line tested, with an $I C_{50} / 24 \mathrm{~h}$ ranging from 33.2 to $161.2 \mu \mathrm{M}$.

We evaluated the effect of diterpenoids against intracellular $\mathrm{T}$. cruzi forms by immunofluorescent identification of a specific membrane molecular marker (Ssp-4 antigen) of the T. cruzi amastigote forms. The accuracy and reproducibility of the measurements were found to be outstanding when examined by confocal microscopy.

Key words: Trypanosoma cruzi - intracellular amastigotes - lysis - diterpenoids -Azorella compacta - chemotherapy confocal microscopy

Chagas disease caused by Trypanosoma cruzi is a major public health problem in South America where nearly 20 million people are infected by T. cruzi and 90 million are at risk in endemic areas (WHO 2000).

There is no satisfactory chemotherapy for the disease in any of its phases. The two main drugs used in clinical practice, nifurtimox and benznidazole, produce strong side effects and do not eliminate the parasite during shortterm therapies or during the chronic and inapparent phases of the disease (Urbina 1999, Coura \& de Castro 2002). Similarly, there are no adequate chemoprophylactic drugs to be used to eliminate the parasite from the blood of serologically positive donors. The prevention of transfusion-associated Chagas disease has been attempted through clinical and serologic screening of blood donors and/or by the addition of trypanomicidal substances such as gentian violet to store blood for $24 \mathrm{~h}$. However the

The present study was supported by grants from International Foundation for Science grant F/2565-1, from Fondo Nacional de Desarrollo Científico y Tecnológico de Chile grant 1011068, Dirección de Investigación Universidad de Antofagasta and from the Fundação de Amparo à Pesquisa do Estado de São Paulo.

${ }^{+}$Corresponding author. Fax: +56-55-637802. E-mail: jearayar@uantof.cl

Received 14 March 2002

Accepted 12 December 2002 compounds confers a blue color to the recipients and its use has been restricted in endemic areas. This dye kills trypomastigotes in vitro at $4^{\circ} \mathrm{C}$. When used in concentrations of $125 \mathrm{mg} / 500 \mathrm{ml}$, and the blood is stored for $24 \mathrm{~h}$ before use, transmission is avoided. This strategy has been used extensively in some countries, like Brazil, without apparent side effects, except that patients may become stained for short periods of time (Schmunis 1999).

Due to the high costs involved in the development and registration of new drugs, the pharmaceutical industry has withdrawn funds for research and development of new compounds for the treatment of tropical diseases. Therefore, there is an urgent need to support novel research on natural products with anti-T. cruzi activity (WHO 2000).

The high altitude and desert-like environment of the Andean Mountains in Northern Chile allow the growth of a native macroflora under extreme conditions. Two plants, yareta (Azorella compacta) and chuquican (Mulinum crassifolium), from the Umbelliferae family are rich sources of diterpenoids, compounds with a variety of biological activities (Esquivel et al. 1989, Loyola et al. 1996, 1997a). Both plants are extensively used in folk medicine against diabetes, bronchitis, high-altitude sickness, pneumonia, rheumatism, and have also wound healing effects (Gunckel 1967, Wickens 1995).

In previous studies (Neira et al. 1998), diterpenoids from $A$. compacta showed activity against extracellular amastigotes from highly infected Vero cells. These results do not show what would be the real activity of these compounds against amastigotes since these are intracellular forms of the parasite; therefore, drugs should enter the 
host cell and maintain inside their amastigocidal activity. In the present study, we address this problem by evaluating the anti-T. cruzi activity of five diterpenoids isolated from $A$. compacta, against the intracellular amastigote forms, introducing confocal microscopy as an analysis tool.

\section{MATERIALS AND METHODS}

Extraction and isolation of natural products from $A$. compacta - Plants were collected in the El Tatio area, 4,000 $\mathrm{m}$ above sea level. A voucher specimen was deposited at the herbarium of Universidad de Concepción, Concepción, Chile, and identified by Prof. C Marticorena. The dried and finely powdered whole plant was extracted at room temperature with petroleum ether (PE), followed by extraction with dichloromethane and finally with ethanol:water (1:1). The solvent was eliminated using a rotary evaporator at approximately $40^{\circ} \mathrm{C}$, and different extracts were obtained. The extracts were submitted to chromatography on silica gel, alumina or Sephadex LH-20 columns and eluted with a solvent mixture of increasing polarity (0-100\% EtOAc-PE, or $\left.\mathrm{CH}_{2} \mathrm{Cl}_{2}-\mathrm{MeOH}\right)$. Compound separation was monitored by thin-layer chromatography. The compounds were isolated and purified through column and thin-layer chromatographies, and the derivatives were submitted to crystallization, sublimation and vacuum distillation, as previously described (Loyola et al. 1996). The structure of the natural products was determined by spectroscopic techniques in homo- and heteronuclear 2DNMR experiments (Loyola et al. 1996).

Natural products - All pure compounds from A. compacta were dissolved in water with $1 \%$ dimethyl sulfoxide (DMSO) at a final concentration of $10 \mathrm{mM}$. DMSO was filtered in Millepore $(0.2 \mu \mathrm{m})$ membrane and aseptically added to the tubes.

Cell cultures - Vero cells, HeLa cells, and J-774 murine macrophages were maintained in RPMI 1640 medium supplemented with $10 \%$ fetal bovine serum at $37^{\circ} \mathrm{C}$, in 75 $\mathrm{cm}^{3}$ growth flasks, using a cell culture incubator under a $5 \% \mathrm{CO}_{2}$ humid atmosphere.

Parasites - Epimastigote, trypomastigote and amastigote forms of the Tulahuen and SPA-14 (González et al. 1995) strains of T. cruzi, were used in this study. We also used the CL Brener clone from the CL strain isolated by Brener and Chiari (1963). Parasites were maintained in Swiss mice and axenic growth medium. Epimastigotes were obtained from LIT medium (Camargo 1964) and trypomastigotes from cell cultures (de Diego et al. 1988). Intracellular amastigotes were obtained by infecting Vero cells and/or HeLa cells with cultured trypomastigotes by the method of González (1991). Extracellular amastigotes were obtained as previously described (Tomlinson et al. 1995).

Determination of the trypanocidal activity of the natural products against different stages of T. cruzi - Experiments were carried out according to González et al. (1990). Firstly, $45 \mu 1$ of each compound were added to the first well of a 96-well microtiter plate and two-fold dilutions were performed to reach a final concentration range of 1 to $125 \mu \mathrm{M}$. Next, each well received $45 \mu \mathrm{l}$ of a suspension containing $4 \times 10^{6}$ epimastigotes and plates were incubated for $18 \mathrm{~h}$ at $28^{\circ} \mathrm{C}$. A viability control (1\% DMSO) and a mortality control (1 mM crystal violet) were included. No effect on drug toxicity attributable to DMSO was observed at the maximum concentration used of $1 \%$. The trypanocidal activity was measured as percent of mortality after microscopic observation of 50 fields. A viability test was performed using an exclusion dye as described (Jacque et al. 1975). Trypanocidal $\mathrm{IC}_{50} / 18 \mathrm{~h}$ against trypomastigotes and extracellular amastigotes was determined as described for epimastigotes, but plates were incubated at $37^{\circ} \mathrm{C}$.

Trypanocidal activity against intracellular amastigotes - Five-hundred $\mu 1$ of a suspension containing 7 x $10^{4}$ Vero cells $/ \mathrm{ml}$ were seeded on 24 -well microplates incubated for $18 \mathrm{~h}$ under a $5 \% \mathrm{CO}_{2}$ atmosphere in order to obtain cell adherence. Next, the cells were washed and infected with trypomastigotes of the clone CL Brener at a ratio of 10 parasites per cell, for $3 \mathrm{~h}$. The cells were washed with RPMI to remove extracellular parasites. Finally, the infected culture was treated with each compounds (25 $\mu \mathrm{M})$ for $24 \mathrm{~h}$. Inhibition of intracellular growth was determined by counting the number of intracellular amastigotes in 100 infected cells. In order to compare the results, two parallel procedures were employed: (a) light microscopy of cells stained using the classical May Grünwald-Giemsa method; (b) confocal immunofluorescence microscopy using Mab 1D9, an anti-Ssp-4 monoclonal antibody (Barros et al. 1997).

Cytotoxic activity against mammalians cells - Fivehundred $\mu$ l of a suspension containing $7 \times 10^{4} / \mathrm{ml}$ of Vero cells, HeLa cells or J774 macrophages were added to 24well microplates and the cells were left to adhere and grow for $24 \mathrm{~h}$. Cells were washed with RPMI and incubated with different concentrations of each compound for $24 \mathrm{~h}$. Cytotoxicity was evaluated using exclusion dyes, as indicated previously.

All assays were carried out in triplicate using nifurtimox $(35-173 \mu \mathrm{M})$ and crystal violet $(1 \mu \mathrm{M})$ as controls. $\mathrm{IC}_{50}$ values were determined by probit analysis by the method of Finney (1971).

\section{RESULTS}

Five diterpenoids derived from mulinane and azorellane were isolated from A. compacta extracts (Fig. 1). The chemical structure was elucidated by spectroscopic and chemical methods. The molecules Y-1, Y-4 and Y-5 were chemically identical to mulinolic acid, mulinic acid and mulin11,3-dien-20-oic acid, respectively. Their carbon skeleton corresponded to mulinane and they have been previously isolated from Mulinum crassifolium (Loyola et al. 1996, 1997a). Two other molecules were detected for the first time and were denominated azorellanol (Y-2) and desacetylazorellanol (Y-3) because they have a cyclopropane ring between carbons C-9 and C- 12 of the mulinane skeleton. This new carbon skeleton was named azorellane (Loyola et al. 1997b).

The in vitro trypanocidal activity of these diterpenoids against different stages of the Tulahuen and SPA-14 strains and the CL Brener clone of T. cruzi is shown in Table I. At $10 \mu \mathrm{M}$, after $18 \mathrm{~h}$ incubation, only two molecules, the azorellanol (Y-2) and mulin-11,13-dien-20-oic acid (Y-5), 
showed a strong trypanocidal activity with a percentage of cell lysis ranging between $88.4 \pm 0.6$ and $99 \pm 1$ for all the strains and stages studied. The $\mathrm{IC}_{50}$ ranged from 20 to $84 \mu \mathrm{M}$ for $\mathrm{Y}-2$ and from 41 to $87 \mu \mathrm{M}$ for $\mathrm{Y}-5$ in assays against the different developing forms studied (data not

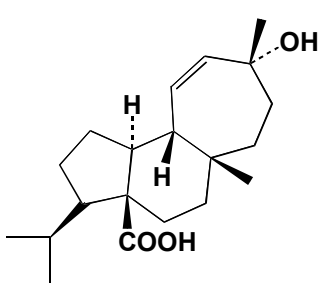

$\mathrm{Y}-1$

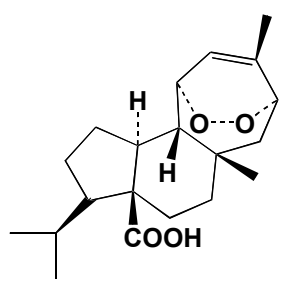

Y-4

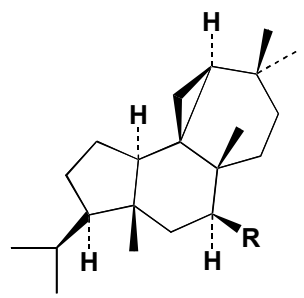

$\begin{array}{ll}\mathrm{Y}-2 & \mathrm{R}=\mathrm{OAC} \\ \mathrm{Y}-3 & \mathrm{R}=\mathrm{OH}\end{array}$

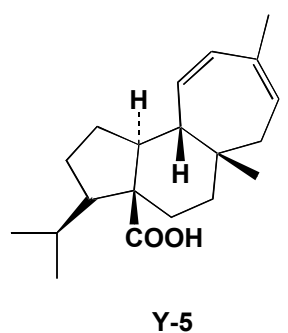

Fig. 1: structure of diterpenoids isolated from Azorella compacta; the molecules Y-1, Y-4 and Y-5 are mulinolic acid, mulinic acid and mulin-11,3-dien-20-oic acid, respectively. Y-2 and Y-3 were identified for the first time and were denominated azorellanol and desacetylazorellanol because they have a cyclopropane ring between carbons C-9 and C-12 of the mulinane skeleton. shown). At $1 \mathrm{mM}$, gentian violet used as control shown a $100 \%$ lysis.

Table II shows the cytotoxic activity of the various compounds against different mammalians cells. Compounds $\mathrm{Y}-1, \mathrm{Y}-3$ and $\mathrm{Y}-4$ showed no cytotoxic activity. The trypanocidal molecules $Y-2$ and $Y-5$ showed different degrees of cytotoxicity depending on the cell line tested, with $\mathrm{IC}_{50}$ ranging between 33.2 and $161.2 \mu \mathrm{M}$ after $24 \mathrm{~h}$ incubation.

At $25 \mu \mathrm{M}$, compounds $\mathrm{Y}-2$ and $\mathrm{Y}-5$ showed trypanocidal activity against intracellular amastigotes of clone CL Brener, inhibiting the growth of the protozoan by nearly $60 \%$ (Table III). After $24 \mathrm{~h}$ incubation at $37^{\circ} \mathrm{C}$, the $\mathrm{IC}_{50}$ for diterpenoids Y-2 and Y-5 was $71.7 \mu \mathrm{M}$ and $49.7 \mu \mathrm{M}$, respectively by May-Grünwald-Giemsa staining, and 32.3 $\mu \mathrm{M}$ and $29 \mu \mathrm{M}$, respectively, by immunofluorescence confocal microscopy (date not shown). These differences could be explained by the fact that Giemsa staining do not measures cell vitality and do not provide information about cell integrity. On the other hand, immunofluorescence allows detection of viable intracellular amastigotes, since they are synthetizing and expressing a particular antigen and also have an intact cytoplasmic membrane as indicated by the reactivity of monoclonal antibody against the Ssp-4 epitope.

Accuracy and reproducibility in detection of viable intracellular amastigotes were greatly improved by the use of confocal fluorescence microscopy. Fig. 2 shows the results of the intracellular amastigote clone CL Brener photographed by confocal microscopy after treatment with Y-2, Y-3 and Y-5 diterpenoids (2, 3 and 4). There was a clear decrease in Ssp-4 labeling in amastigotes treated with $25 \mu \mathrm{M}$ Y-2 or Y-5 when compared with controls (1).

TABLE I

Lysis of epimastigotes (E), trypomastigotes (T) and axenic amastigotes (A) from different Trypanosoma cruzi strains by diterpenoids from Azorella compacta

\begin{tabular}{|c|c|c|c|c|c|c|c|c|c|}
\hline \multirow{3}{*}{$\begin{array}{l}\text { Diterpenoid } \\
(10 \mu \mathrm{M})\end{array}$} & \multicolumn{9}{|c|}{ Population (\% lysis) } \\
\hline & \multicolumn{3}{|c|}{ Tulahuen } & \multicolumn{3}{|c|}{ SPA-14 } & \multicolumn{3}{|c|}{ CL Brener } \\
\hline & $\mathrm{E}$ & $\mathrm{T}$ & A & $\mathrm{E}$ & $\mathrm{T}$ & A & $\mathrm{E}$ & $\mathrm{T}$ & A \\
\hline Y-1 & $2.5 \pm 0.2$ & $3.9 \pm 0.4$ & $3.5 \pm 0.4$ & $2.7 \pm 0.2$ & $3.5 \pm 0.2$ & $3.3 \pm 0.3$ & $1.6 \pm 0.2$ & $2.4 \pm 0.2$ & $2.2 \pm 0.4$ \\
\hline Y-2 & $89 \pm 0.8$ & $97.5 \pm 0.5$ & $95.2 \pm 1.0$ & $98 \pm 0.6$ & $97.4 \pm 0.8$ & $88.4 \pm 0.8$ & $97.3 \pm 0.8$ & $99 \pm 1.0$ & $96 \pm 0.8$ \\
\hline Y-3 & $2 \pm 0.3$ & $2.8 \pm 0.4$ & $2.4 \pm 0.4$ & $3.2 \pm 0.4$ & $3.4 \pm 0.4$ & $3.1 \pm 0.2$ & $2.1 \pm 0.1$ & $2.6 \pm 0.3$ & $2.2 \pm 0.2$ \\
\hline$Y-4$ & $2.2 \pm 0.2$ & $3.1 \pm 0.3$ & $2.9 \pm 0.3$ & $2.5 \pm 0.2$ & $3 \pm 0.4$ & $2.9 \pm 0.3$ & $2.6 \pm 0.4$ & $2.8 \pm 0.2$ & $2.7 \pm 0.3$ \\
\hline Y-5 & $96 \pm 1.0$ & $98.4 \pm 0.6$ & $97.1 \pm 1.0$ & $93 \pm 0.8$ & $97.8 \pm 0.9$ & $95 \pm 0.5$ & $96.7 \pm 0.9$ & $97.2 \pm 0.4$ & $92 \pm 0.6$ \\
\hline
\end{tabular}

TABLE II

Cytotoxic effect $\left(\mathrm{IC}_{50}\right)$ of Azorella compacta diterpenoids on Vero, HeLa, and J-774 macrophages cell lines

\begin{tabular}{|c|c|c|c|c|c|c|c|}
\hline \multirow[b]{3}{*}{ Cells } & \multicolumn{7}{|c|}{$\mathrm{IC}_{50}(\mu \mathrm{M}) / 24 \mathrm{~h}$} \\
\hline & \multicolumn{5}{|c|}{ Diterpenoids } & \multirow[b]{2}{*}{ Nifurtimox } & \multirow[b]{2}{*}{ Crystal violet } \\
\hline & Y-1 & $\mathrm{Y}-2$ & Y-3 & Y-4 & $\mathrm{Y}-5$ & & \\
\hline Vero & $>1000$ & 161.2 & $>1000$ & $>1000$ & 129.3 & 106.4 & 97.0 \\
\hline $\mathrm{HeLa}$ & $>1000$ & 121.2 & $>1000$ & $>1000$ & 143.4 & 103.1 & 21.2 \\
\hline $\mathrm{J}-774$ & $>1000$ & 37.4 & $>1000$ & $>1000$ & 33.2 & 145.5 & 33.3 \\
\hline
\end{tabular}


TABLE III

Trypanocidal effect of Azorella compacta diterpenoids on intracellular amastigotes of the Trypanosoma cruzi clone CL Brener determined by light and confocal immunofluorescence microscopy

\begin{tabular}{lcc}
\hline & \multicolumn{2}{c}{ Number of amastigotes/100 cells } \\
\cline { 2 - 3 } $\begin{array}{l}\text { Diterpenoids } \\
(25 \mu \mathrm{M})\end{array}$ & $\begin{array}{c}\text { Light microscopy } \\
\text { (May Grunwald-Giemsa) }\end{array}$ & $\begin{array}{c}\text { Confocal microscopy } \\
\text { (Immunofluorescence) }\end{array}$ \\
\hline Y-1 & $101.5 \pm 3.5$ & $125.6 \pm 4.4$ \\
Y-2 & $42.3 \pm 0.6$ & $57.7 \pm 0.9$ \\
Y-3 & $104.5 \pm 3.6$ & $132.3 \pm 4.9$ \\
Y-4 & $111.1 \pm 2.5$ & $135.4 \pm 3.3$ \\
Y-5 & $39.6 \pm 0.8$ & $52.5 \pm 1.0$ \\
Nifurtimox $^{a}$ & $37.8 \pm 2.4$ & $41.6 \pm 3.0$ \\
\hline
\end{tabular}

a: control final concentration of nifurtimox $=35 \mu \mathrm{M}$

\section{DISCUSSION}

In many regions of the world plants have been used in traditional medicine. This fact strongly suggests that they contain products with pharmacological activity. Among parasitic diseases, the examples of quinine and artemisin reinforce the idea that plants could be important sources of new pharmaceuticals.

In Chagas disease, most of the attempts to develop an efficient and safe chemotherapy has been unsuccessful. Currently available drugs (nitrofurans and nitroimidazoles), developed empirically over three decades ago, are unsatisfactory due to frequent toxic side effects and limited efficacy, particularly in the prevalent chronic form of the disease. Furthermore, studies of their mechanism of action have shown that their antiparasitic activity is inextricably linked to mammalian host toxicity (Urbina 2002). The efficacy of these drugs also depends on the susceptibility of T. cruzi strains. The drugs are also genotoxic and produce biochemical damage to mammalian tissues. On the other hand, although T. cruzi, requires specific endogenous sterols for cell viability and proliferation, the currently available antifungal sterol biosynthesis inhibitors are not powerful enough to induce parasitological cures of human or experimental infections. However, new triazole antifungal compounds, which are potent inhibitors of the sterol $\mathrm{C} 14$ alpha demethylase of the parasite and have special pharmacokinetic properties, are capable of inducing parasitological cures in murine models of both acute and chronic Chagas disease. They are currently the most advanced candidates for clinical trials in patients with Chagas disease (Molina et al. 2000, Urbina 2001). Allopurinol and related compounds also reduce the parasitemia and induce a negative xenodiagnosis, but these effects may not be permanent, a fact that invalidates their clinical use (Stoppani 1999).

Among the various tests used to evaluate cytotoxicity and the viability of cell cultures exposed to drugs or active compounds, cell line systems such as the one used in the present study are the most sensitive and best reproduce the conditions that may occur in mammals.

In vitro cytotoxicity tests against mammalian cells should be followed by more precise methods, such as cytogenetic activity. Nifurtimox has been shown to be at least four-fold more toxic than benznidazole in a mutagenesis test against Salmonella strain TA100, at a concentration of $35 \mu \mathrm{g}$ per plaque (Ferreira \& Ferreira 1986).

Differents publications have described the trypanocidal effect of natural products and extracts from species of Senecio (Sarti el al. 1984), some naphthoquinones (Pinto et al. 1987), gossypol (Rovai et al. 1990), boldine (Morello et al. 1994), 1,4 naphthoquinones (Morello et al. 1995) and $\beta$-carboline alkaloids (Rivas et al. 1999). In addition, Brengio et al. (2000) have reported that the sesquiterpene lactone dehydroleucodine inhibited the growth of cultured T. cruzi epimastigotes .

Our work shows that azorellanol (Y-2) and mulin-11,3dien-20-oic acid (Y-5) have trypanocidal effects against all developing stages of $T$. cruzi. These appears to be an interesting attribute of these class of compounds, if we consider that several other diterpenoids isolated from plants have shown anti-T. cruzi activities. In fact, earlier studies of Alves et al. (1995) showed that diterpene entkaur-16-en-19-oic acid, isolated from Mikania obtusata displayed trypanocidal activity against trypomastigotes of $T$. cruzi. On the other hand, we have previously reported the trypanocidal activity of two diterpenoids (Azorellanol and mulin-11,13 -dien-20-oico acid) against extracellular amastigotes of the CL Brener clone, SPA-14 and $\mathrm{G}$ T. cruzi strains transformed in axenic culture at $\mathrm{pH}$ 5.0, using the microscopic observation to detect the effect of compounds on amastigote forms (Neira et al. 1998).

Giemsa staining of infected cells has been used for a long time as a routine laboratory procedure for counting intracellular amastigotes. However, this method has been reported to be of low accuracy and with high time consuming (Martinez et al. 2000). This approach is based mainly on the morphological stained parasite identification.

Thus, we propose the use of a complementary method to evaluate the activity of biomolecules against intracellular forms of T. cruzi using immunofluorescence to detect a cell membrane marker, the Ssp4 antigen specific for T. cruzi amastigotes (Andrews et al. 1987, Burleigh \& Andrews 1995). This antigen can be identified with a monoclonal antibody (1D9) that recognizes an Ssp-4 surface glycoprotein which is expressed in all potentially viable intracellular forms of the parasite (Barros et al. 1997).

Confocal scanning fluorescence microscopy has become widely used in cell biology and pathology. Monoclonal antibodies are a powerful tool that enables detailed studies of tissue forms of T. cruzi (Mortara et al. 1999, 2000). Confocal microscope systems can store and process digitalized images that can be readily accessible. Although expensive, this procedure has the significant advantage of being a highly sensitive, specific and reproducible method that would improve the evaluation of the activity of different compounds against the intracellular stages of the parasite.

Finally, we may conclude that two diterpenoid compounds isolated from $A$. compacta showed trypanocidal activity as demonstrated by conventional procedures as well as by immunofluorescence confocal microscopy. The next step will be to determine the pharmacokinetic and pharmacodynamic properties of these natural products. 


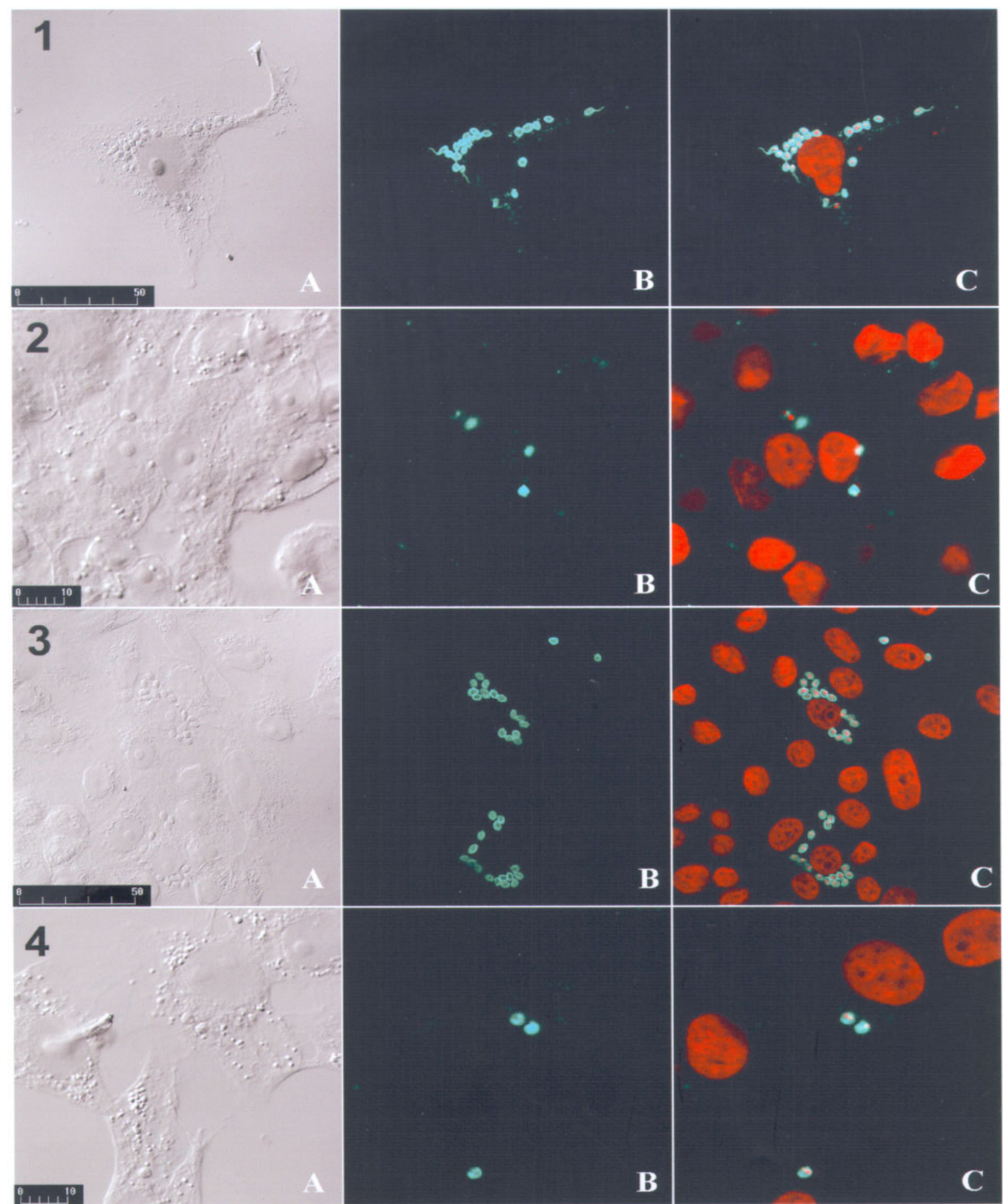

Fig. 2: photomicrographs of intracellular amastigote clone CL Brener after treatment with Y-2, Y-3 and Y-5 diterpenoids (2, 3 and 4). There was a clear decrease in Ssp-4 labeling in amastigotes treated with $25 \mu \mathrm{M} \mathrm{Y-2}$ or Y-5 when compared with control (1).

\section{REFERENCES}

Alves TM, Chaves PP, Santos LM, Nagem TJ, Murta SM, Ceravolo IP, Romanha AJ, Zani CL 1995. A Diterpene from Mikania obtusata active on Trypanosoma cruzi. Planta Med 61: 85-87.
Andrews NW, Hong KS, Robbins ES, Nussenzweig V 1987. Stage-specific surface antigens expressed during the morphogenesis of vertebrate forms of Trypanosoma cruzi. Exp Parasitol 64: 474-484.

Barros HC, Versvick NV, Silva S, Araguth MF, Mortara RA 1997. Distribution of epitopes of Trypanosoma cruzi 
amastigotes during the intracellular life cycle within mammalian cells. J Euk Microbiol 46: 203-233.

Brener Z, Chiari E 1963. Variações morfológicas observadas em diferentes amostras de tripanosomas em meio líquido. Rev Inst Med Trop São Paulo 5: 200-224.

Brengio S, Belmonte S, Guerreiro E, Giordano O, Pietrobom E, and Sosa M 2000. The sesquiterpene lactone dehydroleucodine $(\mathrm{DhL})$ affects the growth of cultured epimastigotes of Trypanosoma cruzi. J Parasitol 86: 407-412.

Burleigh BA, Andrews NW, 1995. The mechanisms of Trypanosoma cruzi invasion of mammalian cells. Annu Rev Microbiol 49: 175-200.

Camargo EP 1964. Growth and differentiation in Trypanosoma cruzi. I - Origin of metacyclic trypomastigotes in liquid medium. Rev Inst Med Trop São Paulo 6: 93-100.

Coura JR, de Castro S L. 2002. A critical review on Chagas disease chemotherapy. Mem Inst Oswaldo Cruz 97: 3-24.

de Diego C, Avendaño C, Alcina A, Carrasco L, Elguero J 1988. Effects of heterocyclic analogues of triphenylmethane dyes against Trypanosoma cruzi. Ann Trop Med Parasitol 82: 235-241.

Esquivel B, Martinez N, Cárdenas J, Ramamoorthy TP, Rodríguez-Hahn L 1989. The pimarene-type diterpenoids of Salvia microphylla var. Neurepia. Planta Med 55: 62-63.

Ferreira RC, Ferreira LC 1986. Mutagenicity of nifurtimox and benznidazole in the Salmonella/microsome assay. Braz J Med Biol Res 19: 19-25.

Finney DJ 1971. Probit Analysis, 3rd ed., Cambridge University Press, Cambridge.

González J, Muñoz S, Ortiz S, Anacona D, Salgado S, Galleguillos M, Neira I, Sagua H, Solari A 1995. Biochemical, immunological and biological characterization of Trypanosoma cruzi population of the Andean North of Chile. Exp Parasitol 81: 125-135.

González J 1991. Antígenos de Superfície de 90 kDa a 35/50 kDa de Formas Metacíclicas de Trypanosoma cruzi: Possivel Papel na Imunidade Protectora contra Infecção Aguda elou Processo de Invasão Celular, PhD Thesis, Escola Paulista de Medicina, São Paulo, 122 pp.

González J, Sagua H, Araya J, Loyola A, Morales G, Pereira J, Estrada M 1990. In vitro activity of natural products against the trypomastigote form of Trypanosoma cruzi. Phytother Res 4: 1-4.

Gunckel H 1967. Fitonimia Atacameña. Rev Univer Norte 30: $1-38$.

Jacque P, Avila JL, Pinardi ME, Convit J 1975. Germicidal activity of a polyenzymic system of pathogenic protozoa in vitro. Arch Int Physiol Biochim Biophys 83: 976-978.

Loyola L, Bórquez J, Morales G, San Martín A 1996. Mulinolic acid, a diterpenoid from Mulinum crassifolium. Phytochemistry 43: 165-168.

Loyola L, Bórquez J, Morales G, San Martín A 1997a. Diterpenoids from Azorella compacta. Phytochemistry 44: 649651.

Loyola L, Bórquez J, Morales G, San Martín A 1997b. Mulinol a diterpenoid from Azorella compacta. Phytochemistry 45:1465-1467.

Martínez RA, Escario JA, Nogal JJ, Gómez A 2000. Evaluation of drug activity against intracellular forms of Trypanosoma cruzi employing enzyme immunoassay. J Clin Pharm Ther 25: 43-47.

Molina J, Martins-Filho O, Brener Z, Romanha AJ, Loebenberg D, Urbina JA 2000. Activities of the triazole derivative SCH 56592 (posaconazole) against drug-resistant strains of the protozoan parasite Trypanosoma (Schizotrypanum) cruzi in immunocompetent and immunosuppressed murine hosts. Antimicrob Agents Chemother 44: 150-155.

Morello A, Lipchenca I, Cassels BK, Speisky H, Aldunate J, Repetto Y 1994. Trypanocidal effect of boldine and related alkaloids upon several strains of Trypanosoma cruzi. Comp Biochem Physiol 107C: 367-371.

Morello A, Pavani M, Garbarino JA, Chamy M, Frey C, Mancilla J, Guerrero A, Repetto Y, Ferreira J 1995. Effects and mode of action of 1,4 naphthoquinones isolated from Calceolaria sessilis on tumoral cells and Trypanosoma parasites. Comp Biochem Physiol 112C: 119-128.

Mortara RA, da Silva S, Taniwaki NN 2000. Confocal fluorescence microscopy: a powerful tool in the study of Chagas' disease. Rev Soc Bras Med Trop 33: 79-82.

Mortara RA, da Silva S, Patricio FR, Higuchi ML, Lopes ER, Gabbai AA, Carnevale P, Rocha A, Ferreira MS, Souza MM, de Franco MF, Turcato G, Ferraz Neto BH 1999. Imaging Trypanosoma cruzi within tissues from chagasic patients using confocal microscopy with monoclonal antibodies. Parasitol Res 10: 800-808.

Neira I, Poblete L, Porcille P, Silva P, Araya J, Borquez J, Morales G, Loyola LA, Sagua H 1998. Activity of diterpenoids isolated from Azorella compacta (Llareta) on Trypanosoma cruzi amastigotes. Bol Chil Parasitol 53: 9-13.

Pinto A, Ferreira V, Capella R, Gilbert B, Pinto M 1987. Activity of some naphthoquinones on blood streams forms of Trypanosoma cruzi. Trans R Soc Trop Med Hyg 81: 609610.

Rivas P, Cassels B, Repetto Y, Morello A 1999. Effects of some $\beta$-carboline alkaloids on intact Trypanosoma cruzi epimastigotes. Comp Biochem Physiol 122 C: 27-31.

Rovai LE, Aoki A, Gerez de Burgos NM, Blanco A 1990. Effect of gossypol on trypomastigotes and amastigotes of Trypanosoma cruzi. J Protozool 37: 280-286.

Sarti S, Silva J, Santos Filho D, Peto G, Ferreira S, Rossi M, Ribeiro dos Santos R 1984. Controle de transmissão transfusional da doença de Chagas. Avaliação de drogas isoladas a partir de produtos naturais vegetais. XI Reunião Anual de Pesquisa Básica em Doença de Chagas, Caxambu, Brasil, p. 146.

Schmunis G 1999. Prevention of Transfusional Trypanosoma cruzi infection in Latin America. Mem Inst Oswaldo Cruz 94 (Suppl. 1): 93-101.

Stoppani AO. 1999. The chemotherapy of Chagas' disease. Medicina (Buenos Aires) 59: 147-165.

Tomlinson S, Vandekerckhove F, Frevert U, Nussenzweig V 1995. The induction of Trypanosoma cruzi trypomastigote to amastigote transformation by low $\mathrm{pH}$. Parasitology 110 : 547-554.

Urbina JA 1999. Parasitological cure of Chagas disease: Is it possible? Is it relevant? Mem Inst Oswaldo Cruz 94: 349355.

Urbina JA 2001. Specific treatment of Chagas disease: current status and new developments.Curr Opin Infect Dis 14: 733741.

Urbina JA 2002. Chemotherapy of Chagas disease. Curr Pharm Des 8: 287-95.

Wickens GE 1995. Llareta (Azorella compacta. Umbelliferae): a review. Econ Bot 49: 207-212.

WHO - World Health Organization 2000. Special Programme for Research and Training in Tropical Disease (TDR). Natural products for parasitic diseases. TDR News 62: 4. 